\title{
Increasing the Lifetime of Variable Displacement Vane Pump With Aluminium Body
}

\author{
Ahmet Oktay Devecili*, Rifat Yakut*, Alper Tombak* \\ * Hema Endüstri A.S. Organized Industrial Zone, Çerkezköy, 59501 Tekirdağ, Turkey \\ Email: rifatyakut@hattat.com.tr
}

\begin{abstract}
Keywords: Variable displacement vane pump with aluminium body, Anodic oxidation, wearing, coating, steering systems

ABSTRACT. In this study, anodic oxidation method is applied to a flow-regulating valve and valve seat of the variable displacement vane pump with an aluminium body, which is used commonly in commercial vehicle steering systems. Then the lifetime of the pump is tested in a contaminated hydraulic fluid. After the lifetime tests, surfaces of the coatings are characterized with scanning electron microscope (SEM) and energy dispersive X-ray spectroscopy (EDS). The thickness of the coating after the process is measured between 30 and 40 microns, and the hardness of the coating is between 360 and $440 \mathrm{Hv}$. This experiment proved that the resistance of the valve seat increased by between 30 and $40 \%$ after the coating process.
\end{abstract}

\section{INTRODUCTION}

Vane pumps are hydraulic units which are used commonly in modern industry [1-3]. In particular, in the automotive sector, hydraulic steering systems are designed with vane pumps because of their silent operating properties. Vane pumps have more complex designs than other types of pumps. They work according to the principle that the wings carryi hydraulic fluid in the rotor-stator group. These pumps, when used in vehicle systems, acquire the needed stimulation from the variable-speed motors. The pump has to have a flow-regulating valve in order to form the constant flow of hydraulics that a steering system needs [4-7]. High pressure, cycle, and flow cause the hydraulic fluid to become contaminated. This contamination leads to the wearing and degradation of the flowregulating valve and valve seat. There has been various research to calculate and prevent this wearing [8-10], but no literature search shows that there has been a research examining the relation between lifetime and the coating applied to flow-regulating valves and valve seats. In some research, parameters such as coating characteristics, coating thickness, hardness, flow effect, base material effects are examined [11-17]. However, there was no research found that examined the relation between anodic oxidation coating and the performance of the pumps.

In this experiment, a flow-regulating valve seat and the valve bar are coated using the anodic oxidation method. Solutions for wear are examined, and increasing the lifetime of the pumps is targeted.

\section{EXPERIMENTAL PART}

\subsection{Coating of the pumps}

The chemical analysis of the eight pumps to be coated is determined by optic spectrometer and shown in Table 1 with the standard deviations. It is determined that vane pumps are manufactured with an alloy similar to AlSi10. A 3D solid model of the vane pumps to be coated is shown in Fig. 1 Before coating the flow-regulating valve and valve seat, pumps are cleaned in scrubber, then washed with ethyl alcohol and dried afterwards. Then, during the coating process, pumps are coated in $2 \mathrm{M} \mathrm{H}_{2} \mathrm{SO}_{4}$ solution at $10{ }^{\circ} \mathrm{C}$, with a direct current of $8-8,5 \mathrm{~A} / \mathrm{dm}^{2}$ for 60 minutes. The voltage before ending the process was $65 \mathrm{~V}$, and the current was $1.2-1.4 \mathrm{~A} / \mathrm{dm}^{2}$. To prevent temperature rise, water and ethyl glycol $(1: 1)$ are circulated around an electroplating bath. Eight pumps are coated during the process. Pumps 1, 2, 3 and 4 were cut and taken colt mounted in order to 
determine the hardness, thickness, surface roughness and phase analysis. These samples are prepared with 320-2,500 $\mathrm{SiC}$ sandpaper, and polished with 1-3 $\mu \mathrm{m}$ diamond solution for the examinations. Pumps 5, 6, 7, 8 were subjected to a lifetime test. Also, in order to compare the lifetimes, pumps coded $\mathrm{a}, \mathrm{b}, \mathrm{c}, \mathrm{d}$ are subjected to the same lifetime test, using contaminated fluid under the same conditions. The values are converted into graphical data.

Table 1. Chemical compositions of vane pumps coated by anodic oxidation.

\begin{tabular}{|c|c|c|c|c|c|c|c|c|c|c|}
\hline \multicolumn{10}{|c|}{ Chemical Composition of Pumps (wt\%) } \\
\hline Elements & Al & Si & Fe & Cu & Mn & Mg & Zn & Cr & Ni & Ti \\
\hline $\begin{array}{c}\text { Pumps } \\
\text { Analysis }\end{array}$ & 86,9 & 10,3 & 0,787 & 0,352 & 0,504 & 0,75 & 0,145 & 0,0165 & 0,0681 & 0,0176 \\
\hline $\begin{array}{c}\text { Standard } \\
\text { Deviations }\end{array}$ & 0,100 & 0,024 & 0,021 & 0,018 & 0,022 & 0,022 & 0,008 & 0,011 & 0,007 & 0,002 \\
\hline
\end{tabular}



Figure 1.3D solid model cutaway view of coated flow-regulating valve and valve seat of the vane pump.

\subsection{Testing pumps}

After the coating process, the flow-regulating seat of the coated pumps is polished and the desired cylindricality and circularity are applied. Then the coated pumps are used together with other parts, in order to measure the changes in their performance. Coated pumps are operated at $1000 \mathrm{Rpm}$ as shown in Fig. 2 A 25-litre external oil tank is used during the contaminated oil test. The oil used in this test is level 23, and prepared according to ISO 4406 [18] standards. $\mathrm{SiO} 2$ and $\mathrm{Al}_{2} \mathrm{O}_{3}$ abrasive particles, with average size around $10 \mu \mathrm{m}$, are added to the oil in a controlled manner, to prepare the test oil. During the test, in order to maintain the controlled abrasion of the flow-regulating valve and valve seat, a sliding bar was designed. This bar moved back and forth with the help of a pneumatic piston ( 1 second/cycle) during the test. Coated and non-coated pumps were removed from the test mechanism after 5 hours of operation. Then re-worked in clean oil at $1000 \mathrm{Rpm}$, and performance values were taken. During the test, the temperature of the contaminated oil was $75 \pm 5^{0}$ $\mathrm{C}$, and the system pressure was 10 bar. Pump test conditions are shown in Fig. 3 


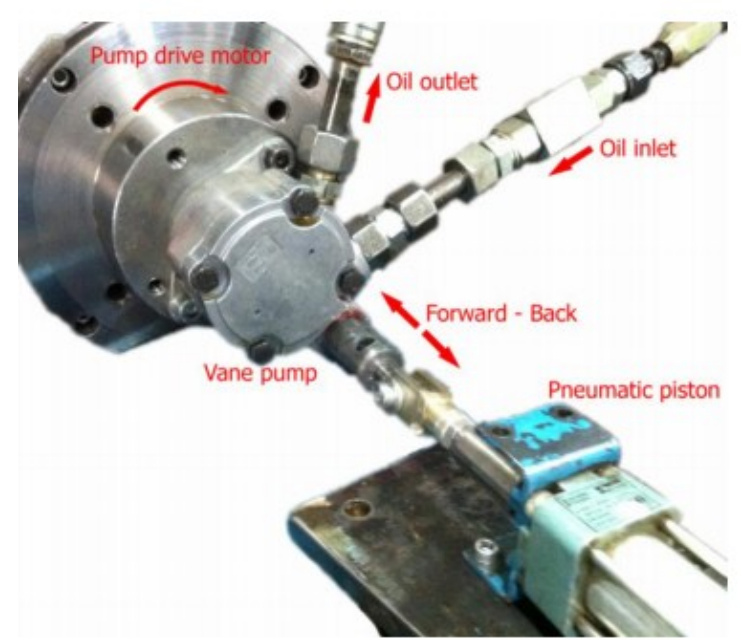

Figure 2. Vane pump lifetime test mechanism

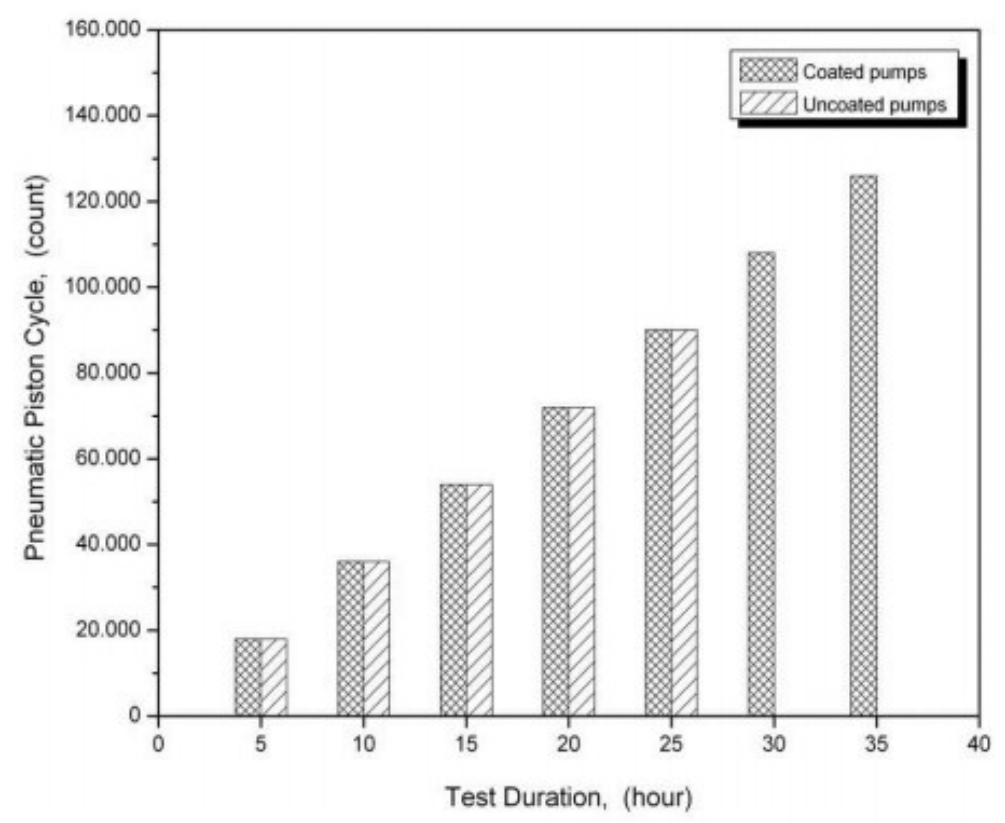

Figure 3. Test times at $1000 \mathrm{Rpm}$, and piston cycle values of the vane pumps with coated flow-regulating valve and valve seat, and non-coated vane pumps in contaminated oil.

\section{RESULTS AND ARGUMENTS}

\subsection{SEM and EDS results}

Fig. 4 shows the SEM image of vane pump with coated flow-regulating valve, after the polishing operation. As shown, the coating thickness is approximately $30 \mu \mathrm{m}$, and the coating surface seems smooth during polishing. No fracture or fissures are observed between coating and base material. It was a successful coating operation. Si particles in the base material can be seen clearly in the SEM image. 


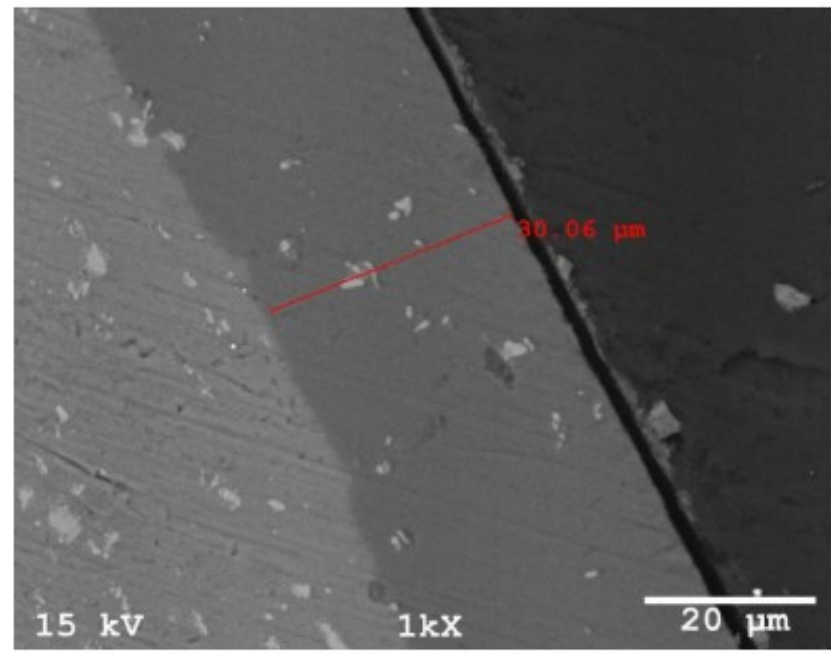

Figure 4. SEM image of the 60 min. coated pump's flow-regulating valve base surface.

Fig. 5 shows the EDS results taken from the coating profile. The coating profile also contains sulphur, as well as oxygen and aluminium. The usage of sulphuric acid in the coating process may be the reason for this.

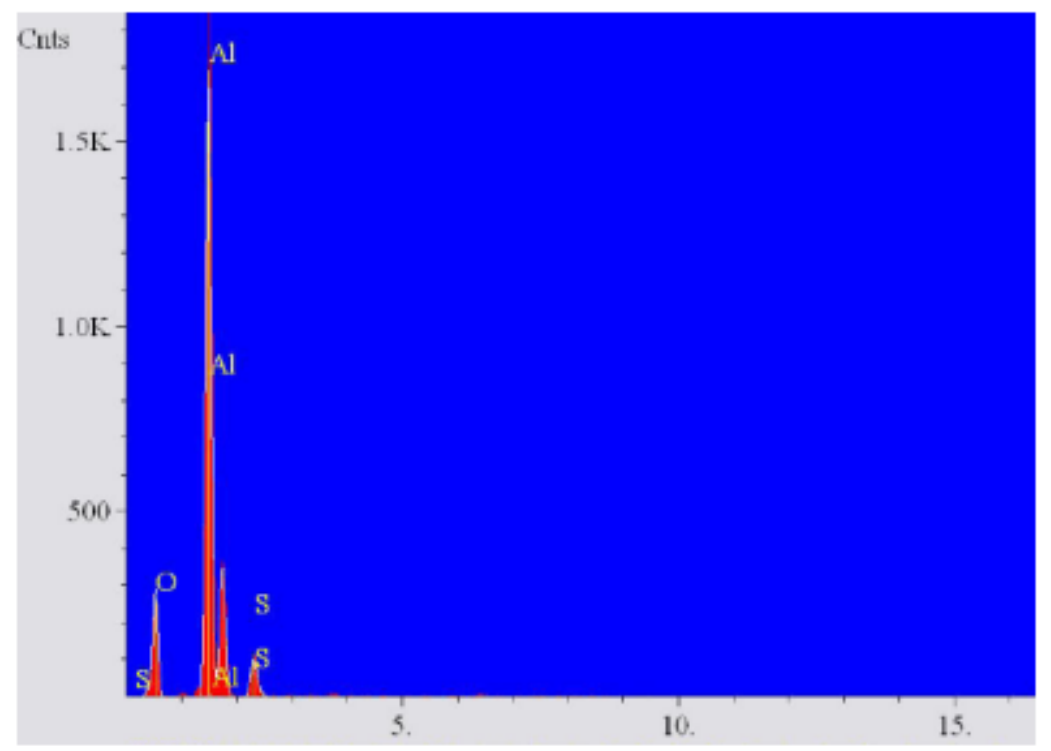

Figure 5. EDS analysis result of the $60 \mathrm{~min}$. coated pump's flow-regulating valve base surface.

\subsection{Micro-hardness results}

Fig. 6 shows the micro-hardness values of $60 \mathrm{~min}$. coated pump's hardness. Hardness value of the pumps is between $360 \mathrm{Hv}$ and $440 \mathrm{Hv}$. The matrix hardness of non-coated pumps is between 30 $\mathrm{Hv}$ and $105 \mathrm{Hv}$. The highest hardness values for base material were seen at intermetallic phases with rich silicon. The lowest hardness value for base material were seen at those sections where aluminium is the only phase. The changes as a result of coating thickness are shown in Fig. 7 It is determined that hardness value lowers outside the base material. The reason for this are the intermetallic phases in the A1Si10 alloy, and the density of oxidation canals formed during the coating process. [11,17] 


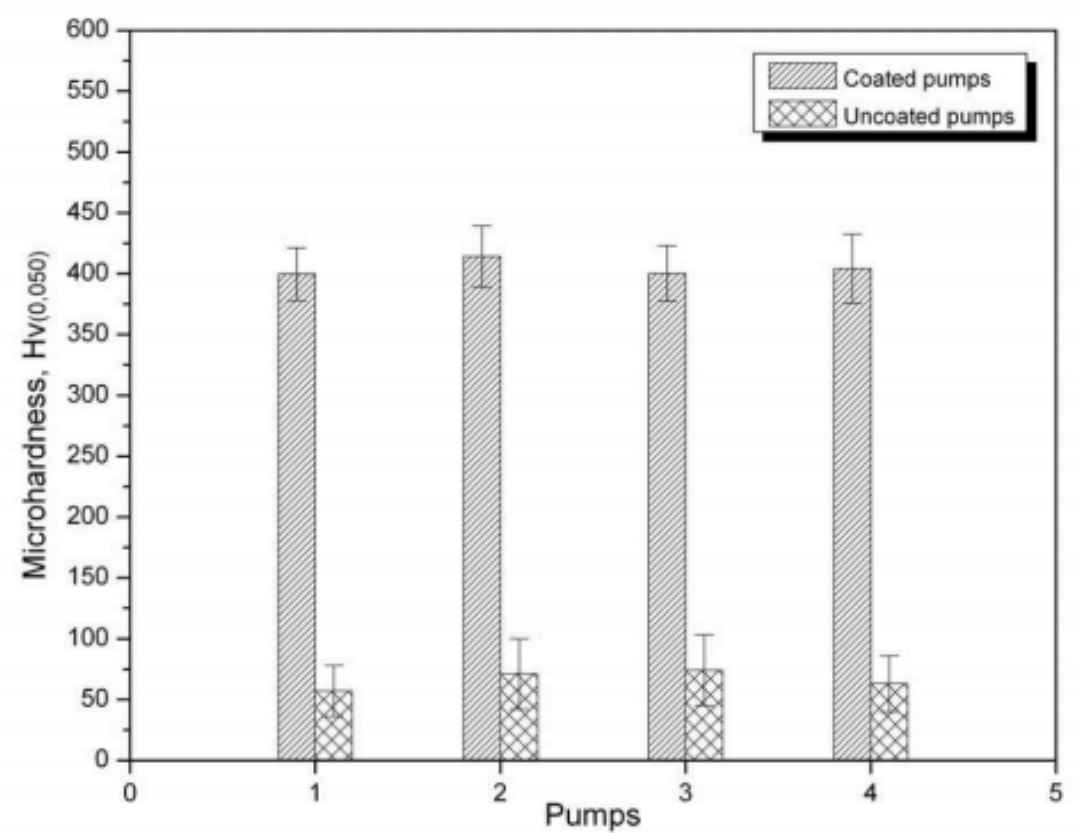

Figure 6. Micro-hardness results of coated and non-coated valve base profile.

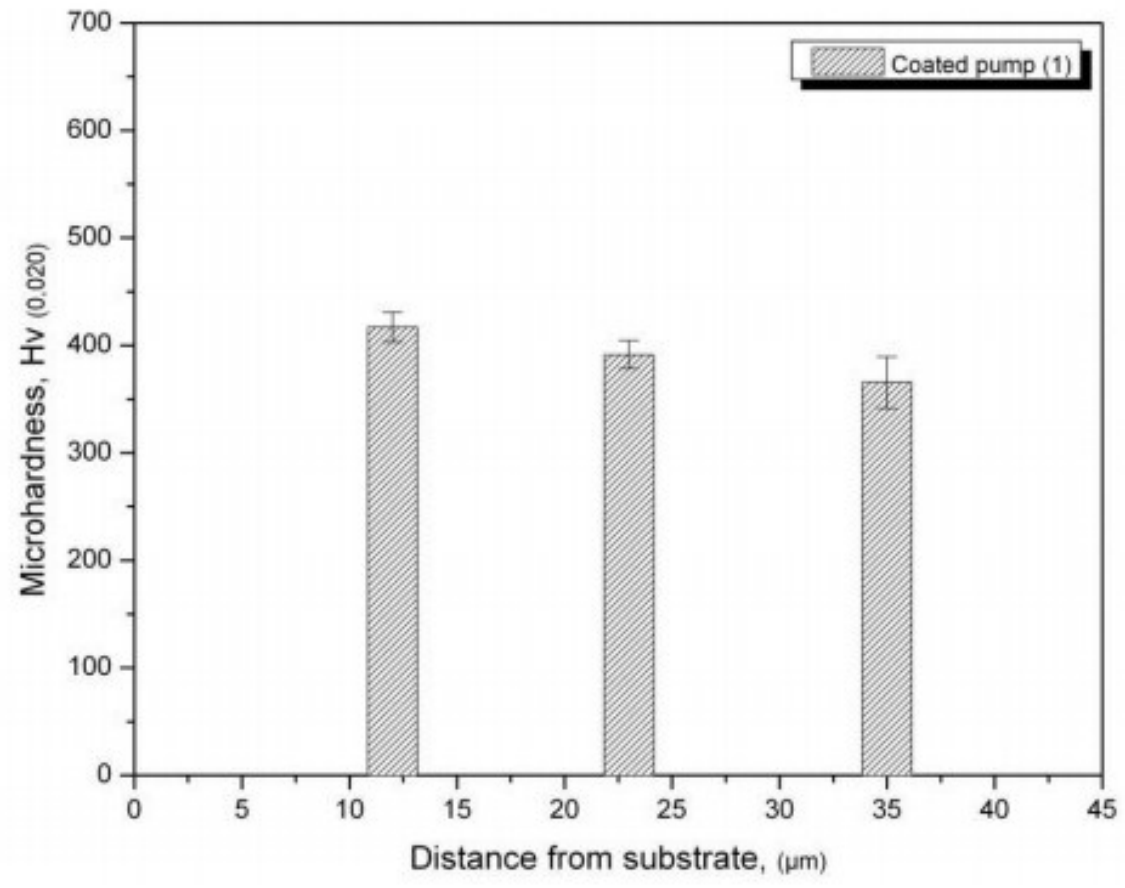

Figure 7. Micro-hardness values across pump 1's coating section.

\subsection{Surface roughness measurement results}

Surface roughness measurements were made by using a 5 - $\mu \mathrm{m}$ radius tip, under a 10 -milligram load, and scanning $15 \mathrm{~mm}$ in 60 seconds. Measurements were repeated 5 times for each pump.

Average roughness values after anodic oxidation coating are shown in Fig. 8 It is determined that roughness increased after coating process. Roughness values before coating were between 0.3 and $0.5 \mathrm{Ra}$, but after the process, the values measured between 3.20 and $3.60 \mathrm{Ra}$. It is determined that oxidation canals, formed during coating process and the growth characteristic of growing coating surface, affect the surface roughness. Fig. 9 shows the surface roughness values after operating for $25 \mathrm{hrs}$ in contaminated oil. Average surface roughness values of both coated and non-coated pumps are increased. This increase is even greater on non-coated pumps. Also, because of the deformation in pumps, error bars of Ra surface roughness increased. This increase is even greater on non-coated pumps. 




Figure 8. Surface roughness values of coated and non-coated pumps before and after polishing.

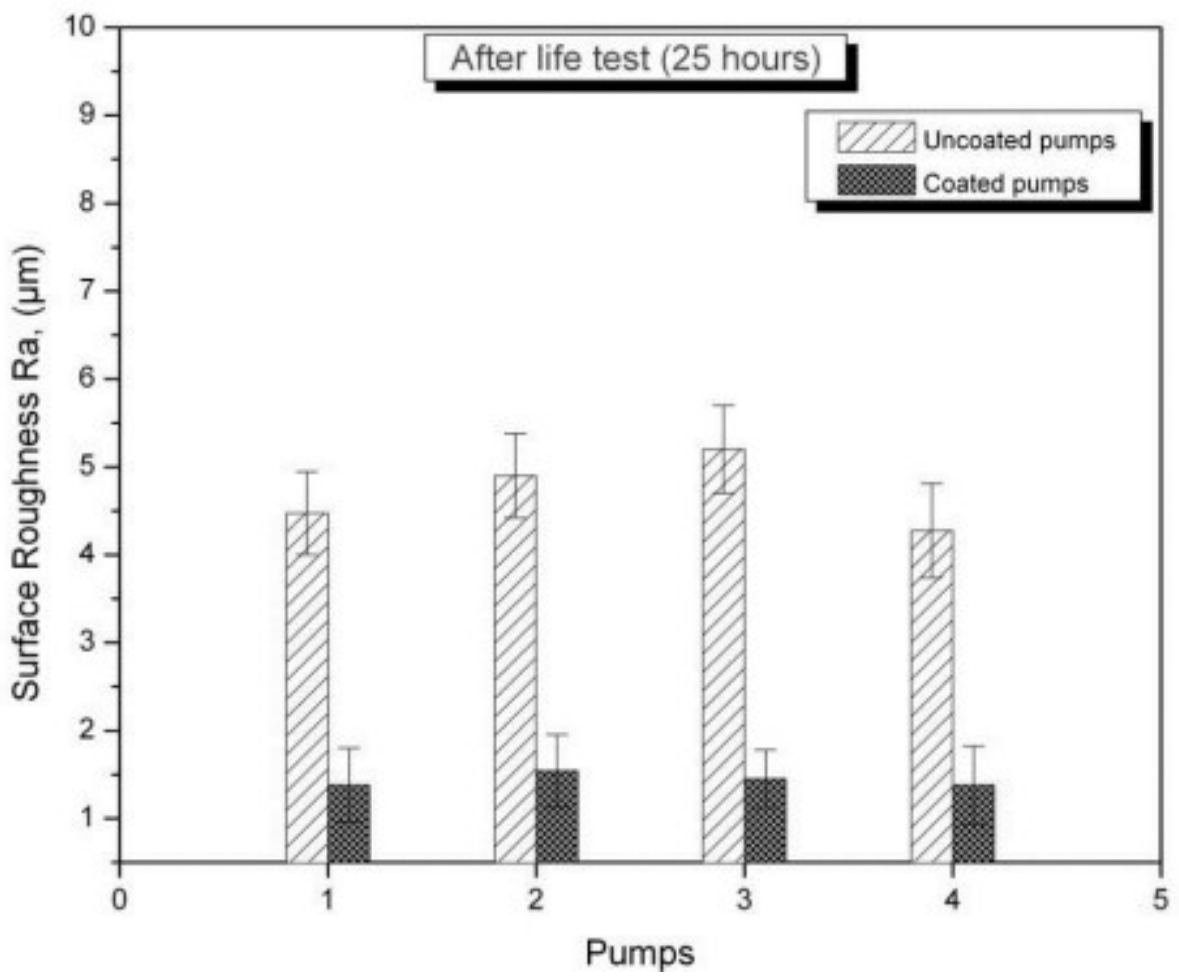

Figure 9. Surface Roughness values of flow-regulating valve seats of coated and non-coated pumps after 25-hr lifetime test in contaminated oil.

\subsection{Lifetime test results of the pumps}

Pumps were removed from the test system with contaminated oil after 5, 10, 15, 20, 25 hrs. Then they were operated in the test system with clear oil at $1000 \mathrm{rpm}$. This process applied to both coated and non-coated pumps, and performance changes in Figs. 10-13 were determined. A reducing valve was used to pressurize the system during measurement. Fig. 10 shows the flow value of a pump operated in contaminated oil for 5 hours. Fig. 11 shows the flow value of a pump operated in contaminated oil for 10 hours. It is determined that the flow value of coated and non-coated pumps changed in a similar way because of the effect of pressure.

Fig. 12 shows the flow values of the pumps operated in contaminated oil for 15 hours. The flow rate of non-coated pumps decreased depending upon the increase in pressure. This indicates that the 
flow-regulating valve and valve seat are damaged. The flow rate decrease is smaller with coated pumps. This means, deformation at the flow-regulating valve and valve seat is less.

Fig. 13 shows that flow rate under pressure decreases in direct proportion to longer operation hours. It is determined that flow values in a lifetime test in contaminated oil do not change much in a nonpressurized environment. However, in a pressurized environment the flow rate decreases rapidly, in direct proportion to the increase in pressure. This indicates that other parts, such as rotor-stator and palettes, are not affected too much by the abrasion in contaminated oil. These parts are made of steel material which is rich in carbon (100Cr6), and their surfaces are hardened by heat treatment.

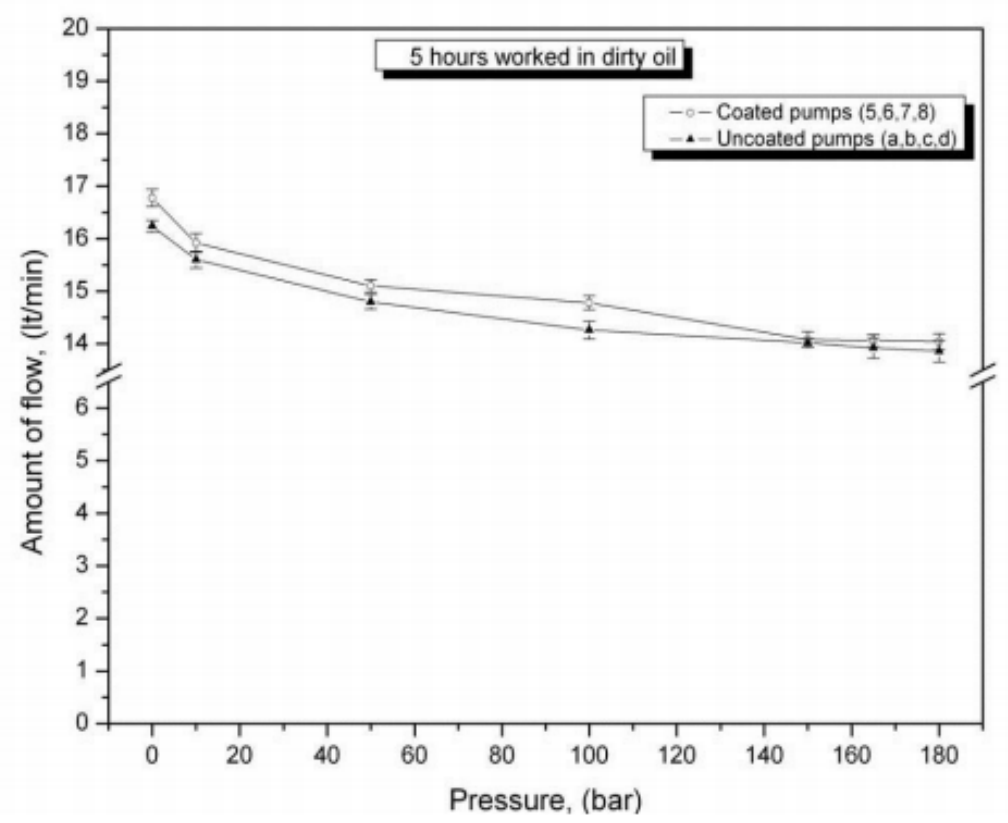

Figure 10. Flow values of coated and non-coated pumps after operating for $5 \mathrm{hrs}$ in contaminated oil.

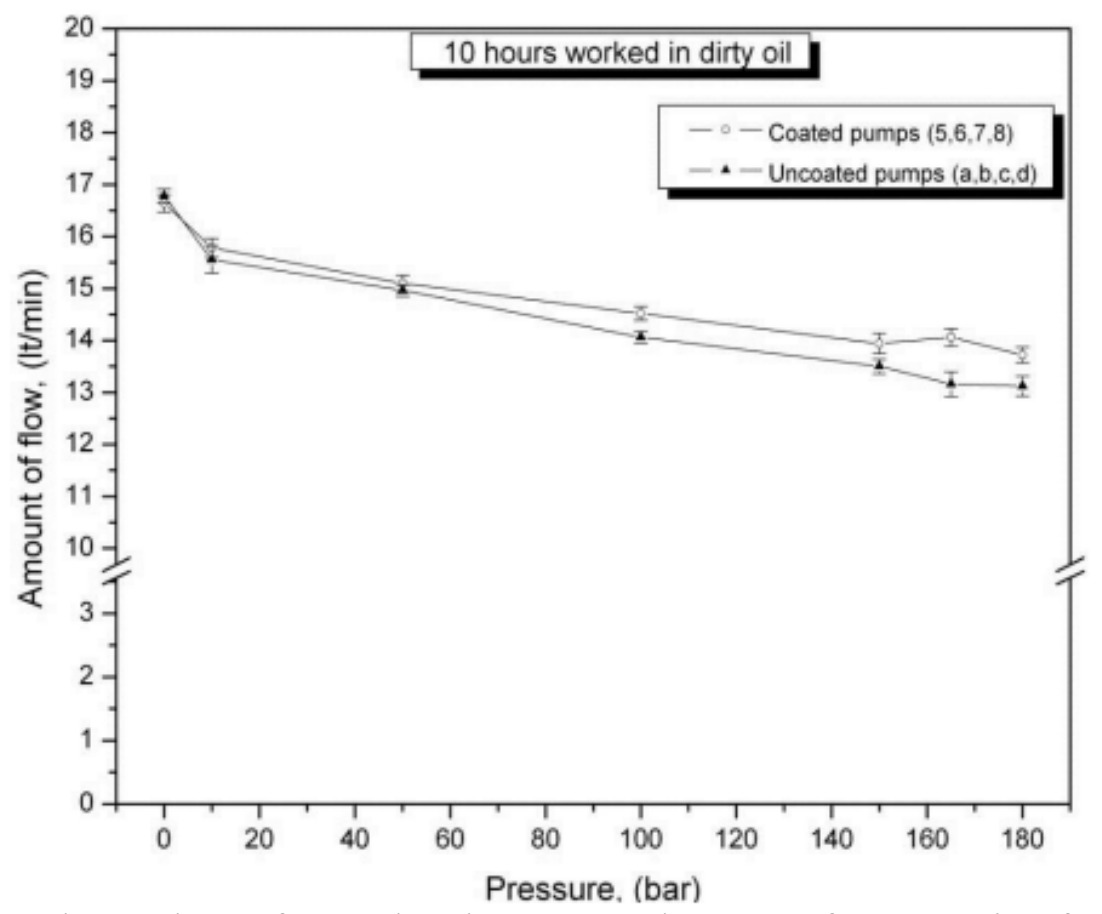

Figure 11. Flow values of coated and non-coated pumps after operating for $10 \mathrm{hrs}$ in contaminated oil. 


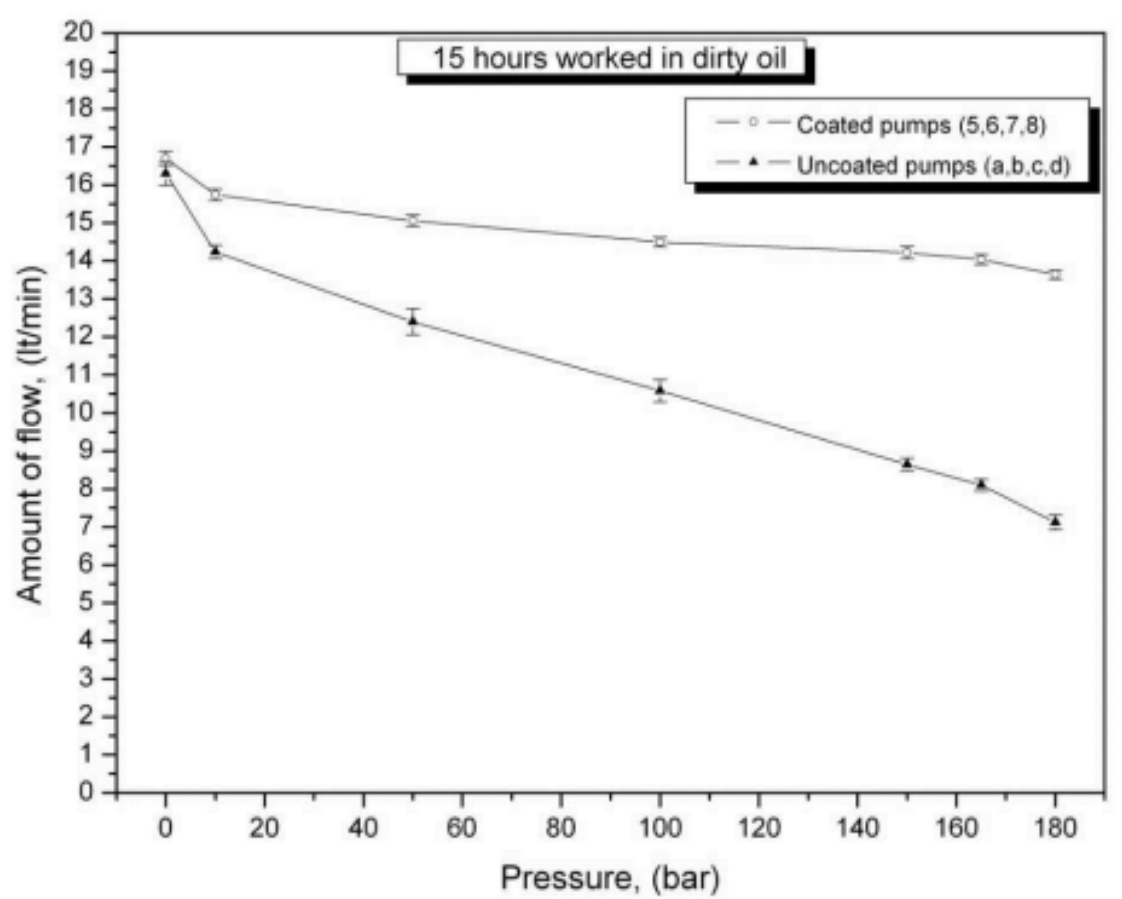

Figure 12. Flow values of coated and non-coated pumps after operating for $15 \mathrm{hrs}$ in contaminated oil.

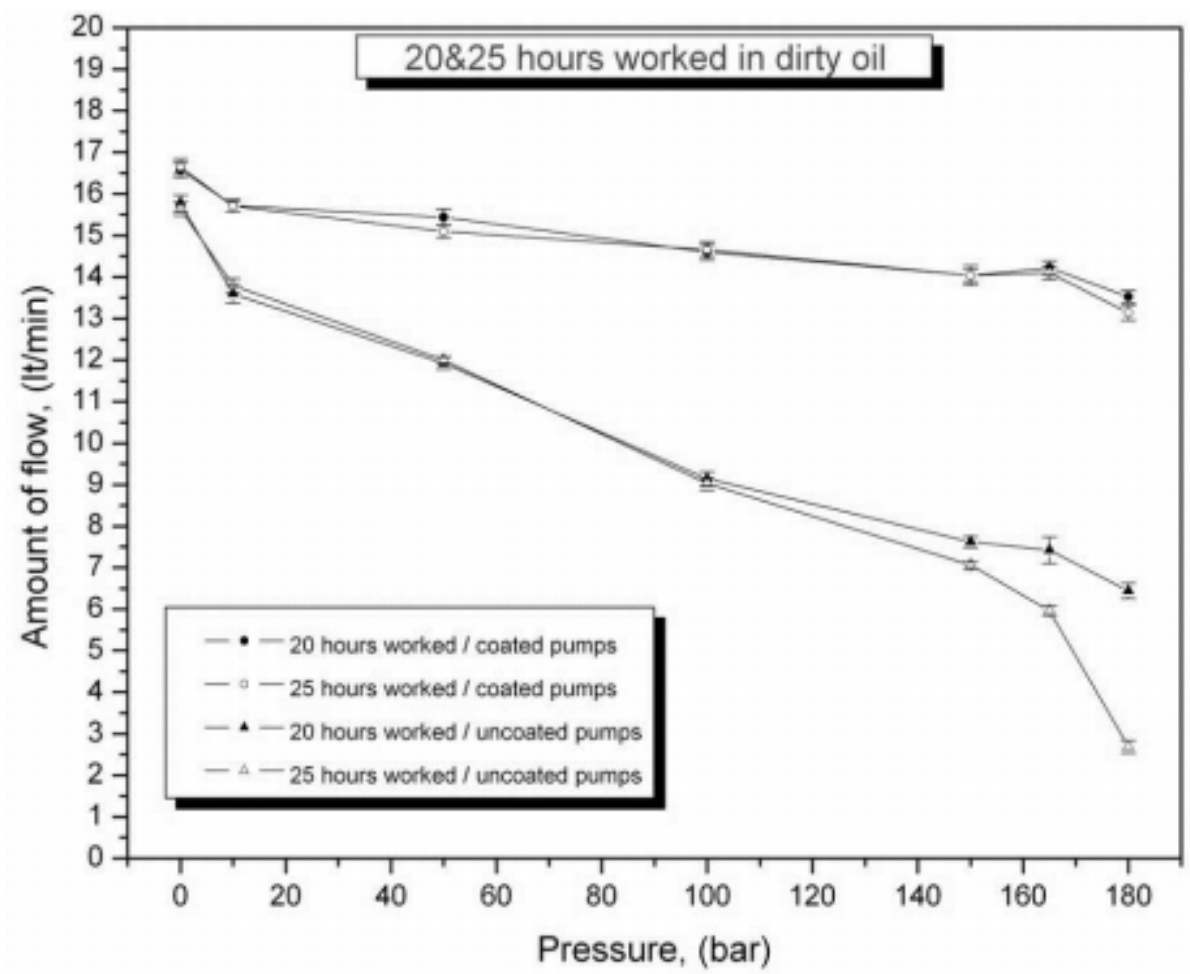

Figure 13. Flow values of coated and non-coated pumps after operating for 20 and $25 \mathrm{hrs}$ in contaminated oil.

\subsection{Macroscopic examination results}

Pump 7 coated with the anodic oxidation method, and non-coated pump b were cut for macroscopic examination. Fig. 14 shows the valve seat of both pumps. It is clear that the valve seat of non-coated pump $b$ is deformed, and there are multiple scratches. On the other hand, deformations and scratches are not so obvious on coated pump 7. 


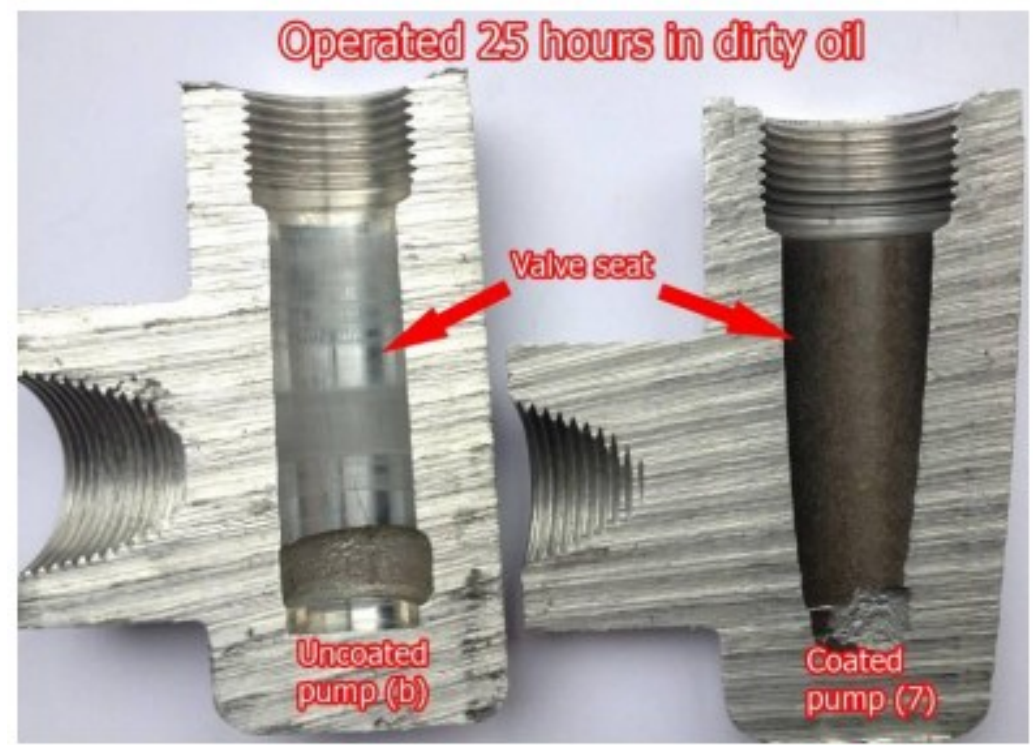

Figure 14. Profile image of Coated Pump 7 and non-coated pump b, after operating for $25 \mathrm{hrs}$ in contaminated oil.

\section{RESULTS AND DISCUSSION}

Flow-regulating valves and valve seats of pumps made of AlSi10 alloy are coated using the anodic oxidation method. The coating thickness after coating process is measured between 30 and $40 \mu \mathrm{m}$. Coating thickness at silicon rich zones is $3-5 \mu \mathrm{m}$ less than other zones. Surface roughness value is increased after coating. It is considered that oxidation canals, formed during coating process, have an effect on this increase.

After anodic oxidation method, the micro-hardness value of the coating is measured at around 400 Hv. It is determined that the hardness value of the coating lowers outside the base material. After the tests, it is determined that pumps with a coated flow-regulating valve and valve seat have, on average, a 30\% longer lifespan than non-coated pumps.

\section{REFERENCES}

[1] R. Doddannavar, A. Barnard and S. Mackay, "Hydraulic Pumps," Practical Hydraulic Systems, pp. 37-68, 2005.

[2] P. E. Nolan, "Pump Types and Applications," Firewater Pumps at Industrial Facilities (Seccond Edition), Vol. 6, pp. 37-53, 2011.

[3] R. O. Garbus, T. L. Angle, K. Blanchard, R. L. Cusworth, K. Desai, M. Gottliebson, D. A. House, J. K. Jackson, R. R. Langteau, C. Martin, S. G. Miller, R. Nickel, L. G. Sloan, E. C. Smith and R. E. Starke, "Types of Pumps," Pumping Station Design (Third Edition), Vol. 11, pp. 1-41, 2008.

[4] Z. Filipi, "Hydraulic and Pneumatic Hybrid Powertrains For Improved Fuel Ecomomy in Vehicles," Alternative Fuels and Advanced Vehicle Technologies For Improved Environmental Performance, pp. 505-540, 2014.

[5] W. E. B. Forsthoffer, "Pump Mechanical Design," Forsthoffer's Rotating Equipment Handbook, Vol. 1, pp. 89-107, 2005.

[6] Y. Lu, Y. Zhao, G. Bu, and P. Shu, "The Integration of Water Vane Pump and Hydraulic Vane Motor for a Small Desalination System," Desalination, Vol. 276, No. 1-3, pp. 60-65, 2011.

[7] A. Parr, "Hydraulic Pumps and Pressure Regulation," Hydraulics and Pneumatics (Third edition), pp. 31-49, 2011.

[8] H. M. Gabriel, F. Schmidt, E. Broszeit and K. H. Kloos, "Improved Component Performance of Vane Pumps by ion-Plated TiN Coatings," Thin Solid Films, Vol. 108, No. 2, pp. 189-197, 1983. 
[9] A. Kunz, B. Matthes, E. Broszeit and K.-H. Kloss, "Application of TiN-Coated Bushings in The Standard Method for Indicating The Wear Characteristics of Hydraulic Fluids in Vane Pumps," Wear, Vol. 162-164, Part B, pp. 966-970, 1993.

[10] R. Gellrich, A. Kunz, G. Beckmann and E. Broszeit, "Theoretical and Practical Aspects of The Wear of Vane Pumps Part A. Adaptation of a Model for Predictive Wear Calculation," Wear, Vol. 181-183, Part 2, pp. 862-867, 1995.

[11] L. E. Fratila-Apachitei, J. Duszczyk and L. Katgerman, "Vickers Microhardness of AlSi(Cu) Anodic Oxide Layers Formed in H2SO4 at Low Temperature," Surface and Coatings Technology, Vol. 165, pp. 309-315, 2003.

[12] F. Xu, Y. Xia and G. Li, "The Mechanism of PEO Process on Al-Si Alloys With The Bulk Primary Silicon,” Applied Surface Science, Vol. 255, pp. 9531-9538, 2009.

[13] M. Song-jiang, L. Peng, Z. Hai-hui, F. Chao-peng, and K. Ya-fei, "Preparation of Anodic Films on 2024 Aluminum Alloy in Boric Acid-Containing Mixed Electrolyte," Transactions of Nonferrous Metals Society of China, Vol. 18, pp. 825-830, 2008.

[14] L. E. Fratila-Apachitei, H. Terryn, P. Skeldon, G. E. Thompson, J. Duszczyk and L. Katgerman, "Influence of Substrate Microstructure on The Growth of Anodic Oxide Layers," Electrochimica Acta, Vol. 49, pp. 1127-1140, 2004.

[15] L. E. Fratila-Apachitei, I. De Graeve, I. Apachitei, H. Terryn, and J. Duszczyk, "Electrode Temperature Evolution During Anodic Oxidation of AlSi $(\mathrm{Cu})$ Alloys Studied in The Wall-Jet Reactor," Surface \& Coatings Technology, Vol. 200, pp. 5343-5353, 2006.

[16] R. Guerrero-Lemus, F. A. Ben-Hander, J. D. Moreno, R. J. Martin-Palma, J. M. MartinezDuart, P. Gomez-Garrido, M. L. Marcos and J. Gonzalez-Velasco, "Anodic Oxidation of Porous Silicon Bilayers,” Journal of Luminescence, Vol. 80, pp. 173-178, 1999.

[17] L. E. Fratila-Apachitei, F. D. Tichelaar, G. E. Thompson, H. Terryn, P. Skeldon, J. Duszczyk and L. Katgerman, "A Transmission Electron Microscopy Study of Hard Anodic Oxide Layers on AlSi(Cu) Alloys,” Electrochimica Acta, Vol. 49, pp. 3169-3177, 2004.

[18] "Hydraulic fluid power-fluids-method for coding level of contamination by solid particles," International Standard ISO 4406, 1987. 